INTERNATIONAL JOURNAL OF ENGINEERING TECHNOLOGY AND SCIENCES (IJETS)

\title{
Natural Fibre Reinforced Polymer Composite (NFRPC) from Waste Polypropylene Filled with Coconut Flour
}

\author{
Ibe Kevin Ejiogu ${ }^{1,2 *}$ Uche Ibeneme ${ }^{2,4}$, Gabriel Osi Tenebe ${ }^{2,4}$, Mark Dada Ayo ${ }^{3}$, Mosunmade $^{2}$ \\ Olukemi Ayejagbara \\ ${ }^{1}$ Nigerian Institute of Leather and Science Technology (NILEST), Directorate of Research and Development, Zaria, Nigeria. \\ ${ }^{2}$ Ahmadu Bello University (ABU), Department of Chemistry. Zaria. Nigeria. \\ ${ }^{3}$ Auchi Polytechnic, Department of Polymer Technology, Auchi. Nigeria. \\ ${ }^{4}$ Nigerian Institute of Leather and Science Technology (NILEST), Directorate of Polymer and Environmental Technology. \\ Department of Polymer Technology. Zaria. Nigeria. \\ Email: Kevin.edu.research@gmail.com*
}

\begin{abstract}
In the present work the authors prepared a biodegradable composite using waste polypropylene (wPP) and coconut flour (CF). Each polymer composite was prepared with different ratios of $\mathrm{CF}$ introduced in the matrix. The composite prepared contained 10\%, 20\%, $30 \%, 40 \%$ and $50 \% \mathrm{CF}$ respectively. $100 \%$ wPP was the control sample. Investigations were done to find out the effect of the $\mathrm{CF}$ on the mechanical properties of the NFRPC. The composite showed an increase in tensile strength and modulus, flexural strength and modulus, water absorption and impact strength with increase in CF. However there was a slight reduction in density of the NFRPCs with increase in CF due to poor dispersion of the fibres and void spaces in the matrix of the composites. The biodegradation rates of the NFRPCs were higher than that of wPP, with the highest biodegradation rate of $2.93 \%$ at $50 \% \mathrm{CF}$ content after six months. The $\mathrm{CF}$ in the composites helped to increase the biodegradation rate as a result of its hydrophilic nature which permits the ingress of water into the matrix of the NFRPCs which aided degradation by action of micro-organism, photo-thermal and oxidative degradation. NFRPCs produced can be utilised for industrial and domestic applications and can also undergo biodegradation when disposed, indicating a more environmental friendly substitute compared to wPP. However to increase the rate of biodegradation additives such as transition metals may be incorporated into the matrix structure to increase biodegradation at a scale that would be much faster and economically more viable.
\end{abstract}

Keywords - Coconut flour; mechanical properties, biodegradation, waste polypropylene

\section{INTRODUCTION}

Natural fibres are becoming more popular as reinforcement in composites because of various reasons among which are: availability, renewability, cost efficiency, ease of processibility, and most importantly they are more environmentally friendly [1, 2]. Nonrenewable resources are becoming very scarce hence the need to provide renewable sources such as natural fibres is becoming popular. Natural fibres can be used in many ways such as textiles, fabrics, paper, reinforcements, and for biofuel [3]. The need for an improved and cleaner environment had awakened the consciousness of communities all over the world, the unsustainable consumption 
of petroleum and its byproducts have led to the adoption of more environmentally friendly sustainable materials. Natural fibres have been considered as reinforcement for the future with properties comparable to the synthetic fibres [4]. Natural fibres can be defined as fibres that are obtained from natural sources such as plants and animals, they are not synthetic or manmade [5]. Natural fibre reinforced polymer composites (NFRPCs) became popular as a result of numerous advantages and wonderful properties natural fibres possess over synthetic fibres some of which are: low weight, low cost, little or no damage to processing equipment, good mechanical properties, processibility, limited health hazards and biodegradability. NFRPCs can be produced by incorporating the natural fibres into polymers (thermoplastic and thermosets) [6].

Even though the natural fibres have numerous advantages when utilised as fibres in polymers to produce NFRPCs they also come with their numerous challenges some of which are poor thermal stability and poor interfacial adhesion between the polymers and natural fibres [7, 8, 9]. The natural fibres consist of lignin, pectin, and cellulolisic contents which increases the ingress of water and moisture from the surrounding and this affects the interfacial adhhesion between polymer and fibres, this adhesion problem could also be as a result of the hydrohilic nature of the fibre incontact with hydrophobic non polar polymer matrix [10]. These are some of the reason of poor transmission of stress from matrix to fibre in the NFRPCs. Modification of natural fibres is thus one of the methods to reduce the short commings encountered in the interaction between natural fibres and the polymer in NFRPCs. Modifications may involves chemical treatment such as alkalisation which changes the composition of the fibre structure and cuase a significant reduction in moisture absorption of the natural fibres which will lead to a better interfacial adhesion between fibre and the polymer matrix [11]. Treating the natural fibres with chemicals will cause them to lose some of their hydroxyl groups and this will reduce the hydrophilic behaviour of the fibres. The chemical compositions of common natural fibres are shown in Table 1.

Table 1: Chemical composition of common natural fibres [12]

\begin{tabular}{ccccc}
\hline Fibre & Cellulose $(\mathrm{wt} \%)$ & Hemicellulose (wt \%) & Ligning (wt \%) & Waxes (wt \%) \\
\hline Rice straw & $41-57$ & 33 & $8-19$ & $8-38$ \\
Rice husk & $35-45$ & $19-25$ & 20 & - \\
White straw & $38-45$ & $15-31$ & $12-20$ & - \\
Curaua & 73.3 & 9.9 & 7.5 & - \\
Pineapple & 81 & - & 12.7 & - \\
Oil palm & 65 & - & 29 & 2 \\
Sisal & 65 & 12 & 9.9 & 3 \\
Coir & $32-43$ & $0.15-0.25$ & $40-45$ & 0.3 \\
Abacha & $56-63$ & $20-25$ & $7-9$ & 0.8 \\
Ramie & $69-76$ & $13-16$ & $0.6-0.7$ & 0.5 \\
Hemp & 68 & 15 & 10 & - \\
Jute & $61-71$ & $14-20$ & $12-13$ & 1.5 \\
Kenaf & 72 & 20.3 & 9 & - \\
Flax & 71 & $18.6-20.6$ & 2.2 & - \\
Bamboo & $26-43$ & 30 & $21-31$ & 25.3 \\
Bagasse & 55.2 & 16.8 & & \\
\hline
\end{tabular}

The use of NFRPCs are growing in the sciences, engineering and technology and are effectively applied in the automobile, building, construction, sports and aerospace industries [13]. 
Poly propylene (PP) has good physical, mechanical, thermal, and electrical properties and has a wide area of applications in various industrial and domestic applications including the pharmaceutical and medical industries [14]. However, the disposal of polypropylene causes nuisance to the environment because it is non-biodegradable [15]. Waste Polypropylene (wPP) polymers can be used as a matrix in the production of NFRPCs.

Table 2: Natural fibres production capacity in the world [12]

\begin{tabular}{cc}
\hline Fibres source & World production $\left(10^{6} \mathrm{~kg}\right)$ \\
\hline Abaca & 70 \\
Ramie & 100 \\
Coir & 100 \\
Hemp & 214 \\
Sisal & 375 \\
Grass & 700 \\
Flax & 830 \\
Kenaf & 970 \\
Jute & 2,300 \\
Sugar cane bagasse & 75,000 \\
Bamboo & 30,000 \\
\hline
\end{tabular}

The authors explored the possibility of utilising wPP for NFRPCs by introducing a natural filler $\mathrm{CF}$ into wPP. This work is aimed at eliminating the environmental menace caused by wPP and also harnesses the potential of utilizing $\mathrm{CF}$ as a natural fibre because of its abundance in many tropical countries including Nigeria. Moreso biodegradability can also be introduced in the wPP matrix of the NFRPCs making them more environmentally friendly $[16,17,18,19]$.

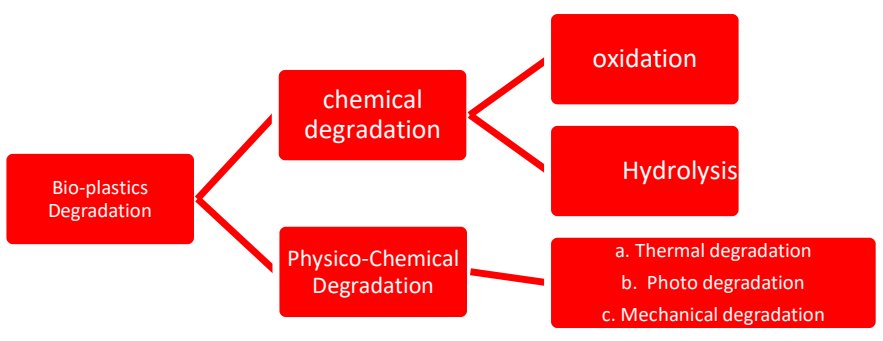

Figure 1: Schematic diagram showing degradation of polypropylene

Figure 1 showed the schematic pathway of the bio-degradation of polypropylene which involves a combination of thermo-oxidative, hydrolysis, mechanical degradation and action of microorganisms. 


\section{METHODOLOGY}

\subsection{Materials}

The polymer matrix utilised in producing the NFRPCs was wPP obtained from Ahmadu Bello Unversity (ABU) dump sites. The reinforcing natural fibres used for this research were coconut shell obtained from Samaru community in Zaria Kaduna State Nigeria.

\subsection{Preparation of $w P P$}

The wPP was washed and allowed to dry in the sun until all surface water have evaporated; it was crushed to a mesh size of $24.5 \mathrm{~mm}$ for easy processibility. The wPP had a density of 0.92 $\mathrm{g} / \mathrm{cm}^{3}$, and a melt flow index $\left(230{ }^{\circ} \mathrm{C}-2.16 \mathrm{~kg}\right)$ of $6.30 \mathrm{~g} / 10 \mathrm{mins}$ [7]. The crushed wPP was kept in a cool dry place.

\subsection{Preparation of Coconut Flour $(\mathrm{CF})$}

The coconut shell was washed thoroughly to remove dirt and was kept under the sun to dry for $24 \mathrm{hrs}$. The coconut shell was broken into smaller pieces with the help of ceramic pestle and mortar; it was then transferred into an electric oven (OV 010) and was heated at a rate of 15 ${ }^{\circ} \mathrm{C} / \mathrm{min}$ at a temperature of $100{ }^{\circ} \mathrm{C}$ to a constant weight. The coconut shell was allowed to cool and crushed using the Thomas Wiley Laboratory Mill Model 4 and was subsequently sieved to obtain a mesh size of $65 \mu \mathrm{m}$. The CF obtained was kept in a desiccator to prevent absorption of moisture which may cause decomposition of the filler.

\subsection{Method}

The coconut flour and wPP were kept in an electric oven at a temperature of $100{ }^{\circ} \mathrm{C}$ for $2 \mathrm{hrs}$ to remove moisture. The moisture content of the coconut flour was less than $3.5 \%$. The heat treatment in the electric oven for matrix and natural fibre were meant to remove moisture which will have a negative affect during melt mixing. The wPP and coconut floor were melt mixed using a two roll mill (no: 5183 ) at $180{ }^{\circ} \mathrm{C}$ at a rotor speed of $50 \mathrm{rpm}$ for $6-8$ mins. Processing was done at $180{ }^{\circ} \mathrm{C}$ to prevent the degradation of the $\mathrm{CF}$. Different ratios of $\mathrm{CF}$ were melt mixed with the wPP to produce the NFRPCs composites as indicated in Table 3. Samples for the mechanical tests were obtained by placing the sheeted samples in a compression moulding machine at $160{ }^{\circ} \mathrm{C}$ and, at a pressure of $3.5 \mathrm{MPa}$ for 5 mins.

Table 3. Compositions of NFRPCs

\begin{tabular}{cccc}
\hline Designation & wPP & Samples Composition \% & CF \\
\hline CT (Control) & 100 & 0 \\
A & 90 & 10 \\
B & 80 & 20 \\
C & 70 & 30 \\
D & 60 & 40 \\
E & 50 & 50 \\
\hline
\end{tabular}




\subsection{Mechanical Test}

Mechanical tests were carried out at room temperature and normal atmospheric pressure. Test specimens were kept at the same conditions for 24 hrs to allow for homogeneity before the tests were eventually carried out.

Density $(\rho)$

The Density of the NFRPCs was obtained by dividing the mass and volume. The mass was obtained using an electric weighing balance and the volume was obtained by getting the values for length, width and thickness with a vernier caliper. Samples of dimensions $3 \times 10 \times 5 \mathrm{~mm}$ were utilised for the density test.

Density $(\rho)=\frac{M}{V}$

(eqn 1)

where $\mathrm{M}=$ mass of sample, $\mathrm{V}=$ volume of samples

Tensile Strength $\left(\sigma_{s}\right)$ and Tensile modulus $\left(E_{t}\right)$

Tensile strength and modulus (ASTM D 638) were done using the Instron Universal Testing machine type (no: 1186) operated at a cross speed of $2 \mathrm{~mm} / \mathrm{min}$. Dumb bell shaped sample of NFRPCs were produced with a thickness of $3 \mathrm{~mm}$, width at ends of $15 \mathrm{~mm}$, width of narrow panel portion was $8 \mathrm{~mm}$, over all gauge length of $100 \mathrm{~mm}$, a grip distance of $60 \mathrm{~mm}$ and a gauge length of $40 \mathrm{~mm}$.

Tensile strength $\left(\sigma_{s}\right)=\frac{F_{b}}{A}$

(eqn 2)

where $F_{b}=$ Fracture force, $A=$ cross sectional area

Tensile modulus $\left(E_{t}\right)=\frac{\sigma_{s}}{\varepsilon}$

(eqn 3)

where $\sigma_{S}=$ tensile strength at fracture point, $\varepsilon=$ strain on the sample.

Flexural strength $\left(\sigma_{f}\right)$ and Flexural modulus $\left(E_{m}\right)$

Samples of dimensions $3 \times 30 \times 80 \mathrm{~mm}$ were utilized for the flexural test (ASTM D 7264) using the Universal materials testing machine (CAT NR 261).

Flexural strength $\left(\sigma_{f}\right)=\frac{F_{b}}{A}$

(eqn 4)

where $F_{b}=$ breaking force, $A=$ cross sectional area.

Flexural modulus $\left(E_{m}\right)=\frac{\sigma_{f}}{\varepsilon}$

(eqn 5)

where $\sigma_{\mathrm{f}}=$ flexural strength at fracture point, $\varepsilon=$ strain experienced by samples.

Impact strength

The impact test was done using the chappy impact testing machine (type 6957) [ASTM E 23] having a pendulum arm of $4 \mathrm{~J}$. Dimensions of samples were $3 \times 10 \times 55 \mathrm{~mm}$, v-notched. 


\section{Water absorption}

Samples of dimensions of $1 \times 5 \times 2.5 \mathrm{~mm}$ were used. The samples were soaked in water at 23 ${ }^{\circ} \mathrm{C}$ for $24 \mathrm{hrs}$ and subsequently boiled in hot water for $2 \mathrm{hrs}$. The samples were then removed and blotted to remove excess water on the surface and weighed.

$\%$ Water absorption $=\frac{W_{f}-W_{i}}{W_{i}}$

where $W_{f}=$ final weight after immersion in water and boiling; $W_{i}=$ initial weight before immersion and boiling in water.

Note: All physico-mechanical tests were carried out three times and average was recorded.

\subsection{Test for Rate of Biodegradation of Composites}

Sample sizes of $1 \times 5 \times 25 \mathrm{~mm}$ were prepared for the test and were thrown into the natural environment. The rate of bio-degradation was measured by obtaining the loss in molecular weight which was obtained using solution viscometry with an Ubbelohde viscometer over a period of 180 days (6 months) at monthly intervals. p-Xylene was the pure solvent used to dissolve the samples to obtain the various concentrations of polymer solutions for the viscometric analysis for the NFRPCs under investigation. The Mark-Houwink Staudinger parameters ' $K$ ' and ' $a$ ' value for the solvent-polymer system utilised at $308 \mathrm{~K}\left(34.85{ }^{\circ} \mathrm{C}\right)$ were $1.76 \times 10^{-3} \mathrm{~m}^{3} \mathrm{Kg}^{-1}\left(1.76 \mathrm{~cm}^{3} \mathrm{~g}^{-1}\right)$ and 0.83 respectively [20]. The concentrations of the polymer solution utilised for the viscometric test for each of $(\mathrm{CT}, \mathrm{A}, \mathrm{B}, \mathrm{C}, \mathrm{D}$ and $\mathrm{E})$ were $0.1,0.2,0.3$, $0.4,0.5$ and $0.6 \mathrm{~g} / 100 \mathrm{~cm}^{3}$, respectively, for $(0,1,2,3,4,5$, and 6$)$ months respectively. The polymer solution and pure solvent were filtered to remove dirt that can block the capillary tube in the viscometer before starting the viscometric analysis. Flow times were obtained from the known concentrations of the polymer solution and the pure solvent. Graph of reduced viscosity over concentration was plotted, the intercept at zero concentration gave the inherent viscosity $(\eta)$. Mark-Houwink Staudinger equation shown in equation 7 was used to obtain the molecular weights of NFRPCs.

$\eta=K M^{a}$

(eqn 7)

Note: Each month was taken as 30 days in this research.

\subsection{SEM Analysis of Tensile Fractured Surface}

Test samples were analyzed using a JEOL scanning electron microscope (SEM). In the SEM analysis a fine probe of electrons scans the surface of the samples and the signals emanating from the incident site are processed and quantized. All specimens were sputtered with $10 \mathrm{~nm}$ layer of gold prior to SEM observations. The coating aimed to avoid the microscope captured the bias or excess of reflected light and to improve the micro graph image obtained. Each specimen was mounted on the aluminum holder of the microscope using double sided electrical conduction carbon adhesive tabs. The accelerating voltage of $5-15 \mathrm{kV}$ was employed. The SEM analyses of NFRPCs at the tensile fracture surfaces were analysed. 


\section{Results and Discussion}

\subsection{Density and Water Absorption}

Figure 2 (a) showed a slight decrease in density. At CT the density was $0.95 \mathrm{~g} / \mathrm{cm}^{3}$ while the densities of NFRPCs ranged from $0.94-0.93 \mathrm{~g} / \mathrm{cm}^{3}$. Sample E showed a percent reduction of 1.06. This could be attributed to adhesion problems due to the incompatibility of hydrophilic CF and hydrophobic matrix. The slight reduction in density could also be attributed to dispersion problems which resulted in void spaces within the matrix the NFRPCs which resulted in lower densities. This trend was observed in the work of Dan-asabe, [21] where he reported that the density of PVC composite produced decreased as the filler loading increased.

Figure 2 (a) also showed the water absorption of NFRPCs were higher than CT and increased as the $\mathrm{CF}$ in the composite increased. This was due to the hydrophilic polar nature of natural fibre composite which has hydroxyl groups that could easily bound to water. NFRPCs had higher water absorption of $1.40 \%$ and $1.60 \%, 2.00 \%, 2.30 \%, 2.50 \%$ and $2.80 \%$ for A, B, C, D, and E respectively for the NFRPCs compared to wPP of $1.40 \%$. This work is similar to the work of Ashori and Nourbakhsh (14) who showed in their work that there was increased water absorption in the polypropylene composite with increase in the natural fibre content.

The increased water absorption in the NFRPCs can also be attributed to lack of treatment of the natural fibre as untreated fibres tend to draw more water than treated fibres. Treatment can be achieved through alkalization, bleaching and acetylation. The work of Sreekala and Thomas [22] showed that treatment of the fibres through modifications by silane treatment, gamma irradiation, latex coating, acetylation, peroxide treatment, and isocyanate had a pronounced effect on the reduction of the moisture content of the OPEFB fibre.

\subsection{Tensile Strength and Young Modulus}

Figure 2(b) showed the tensile strength and modulus of wPP and NFRPCs. The composites had a higher tensile strength and modulus than the wPP, and increased as the percentage of CF introduced in the composite increased due good interfacial adhesion, relatively good dispersion of fibre and good stress transfer between the polymer matrix and the and CF [21]. In the study of Xu et al., [23] he reported that the tensile strength and modulus of the composite was strongly affected by the size of the particle, matrix and fibre bonding, and amount of fibre loading. Modifications in these properties have an effect on the tensile strength and modulus of the composite to withstand higher stress. In another study Ou et al., [32] showed that the strength and modulus of wood flour/high-density-polyethylene composites (WF/HDPE) increased as the amount of Kevlar fibres (KF) introduced in the WF/HDPE increased with the composite containing the grafted KF showing superior tensile strength due to good interfacial adhesion. In another study Prasanth et al., [33] it was shown that less milled surface damages and smooth cutting edges can be seen on the GFRP composite laminate this was due to the use of two-fluted carbide-coated customized tool 3 at identified optimum values of spindle speed, feed rate, and depth of cut, while a poor-quality milled surface was observed on using the generalized fourfluted HSS and carbide tools. 


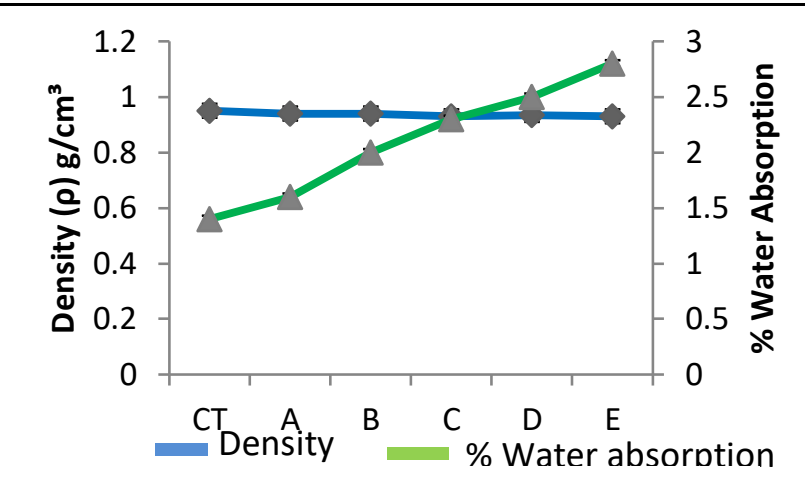

Figure 2a): Density and Water absorption

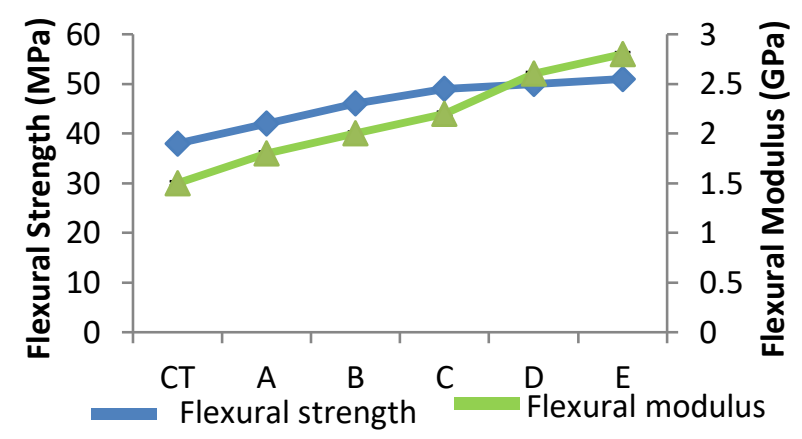

Figure 2c): Flexural Strength and Modulus

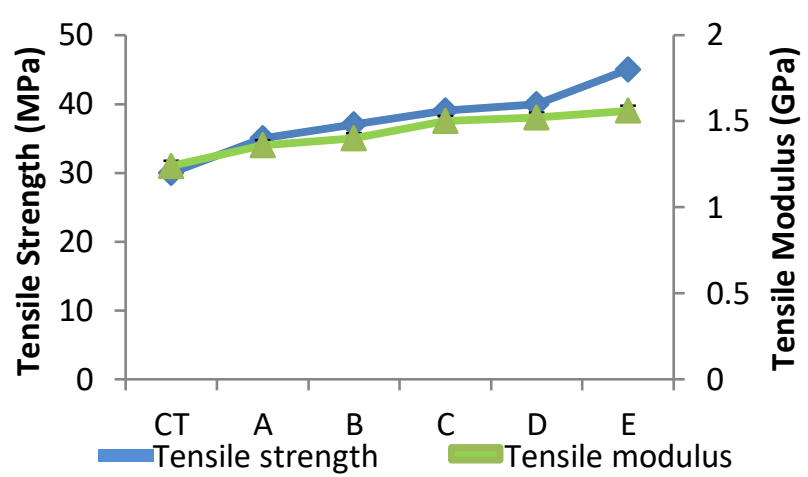

Figure 2b): Tensile Strength and Modulus

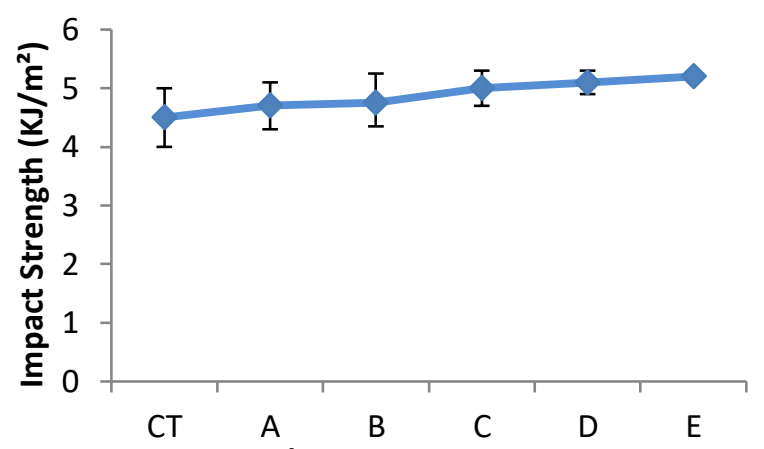

Figure 2d): Impact Strength

Figure 2: Physico- mechanical properties of NFRPCs

\subsection{Flexural Strength and Flexural Modulus}

Flexural strength of the NFRPCs is its ability to resist bending when placed under an applied force. Figure 2 (c) showed the flexural strength and modulus of the NFRPCs. Flexural strength of CT was $20 \mathrm{MPa}$. The flexural strength of the NFRPCs was higher than CT and increased as the percentage of CF increased and recorded the highest flexural strength of $51 \mathrm{MPa}$ at E (50\% of $\mathrm{CF}$ ).

The higher flexural strength and modulus experienced in NFRPCs can be attributed to good interfacial bonding between the matrix and the CF. In the work of Shalwan and Yousif, [24] there were improved mechanical properties of the PP composite with the introduction of hemp, Kenaf and cotton fibres. In another related work Mohanty et al., [25] showed that introduction of jute fibre to Biopol, improved the bending and impact strength by $30 \%$ and $90 \%$ respectively compared to the pure Biopol. In a related study it was stated that the for a composite with twophase matrix and reinforcement, the fibre is very elastic and the polymer is plastic in nature, thus the machining force induced in the cutting tool will vary with respect to matrix and reinforcement when compared to isometric metal- like metallic materials Naresh et al., [34], thus "the possibility of fibre distortion failure from its actual position and matrix infusion takes place at higher machining force". In his work Ejiogu et al., [35] stated that the "higher flexural properties of composites depend on the strength of the interfacial bonding in addition to the strength of the extreme layers of reinforcement in the hybrid composites (Agarwal et al. [36]; 
Abdul et al. [37] while weak matrix/fibre bonding (interfacial) contributes to poor flexural properties (Abdul et al. [37]".

\subsection{Impact Strength}

The notched specimen was tested and Figure 2(d) showed the impact strengths of the NFRPCs. The impact strength of CT was $4.6 \mathrm{KJ} / \mathrm{m}^{2}$. Like the tensile and flexural properties, the impact strength of the NFRPCs increased with the increase in Filler loading. The NFRPCs showed impact strength of 4.70, 4.75, 5.0, 5.10 and $5.2 \mathrm{KJ} / \mathrm{m}^{2}$ for $\mathrm{A}, \mathrm{B}, \mathrm{C}, \mathrm{D}$, and E respectively. The highest impact strength at E showed an increase of $10.6 \%$. The higher impact strength of NFRPCs could be attributed to good packing density of the CF within the matrix of the composite giving it a higher capacity to absorb more energy due to the creation of an efficient path way for matrix- fibre impact stress propagation. The highest impact strength recorded at $C F$ $(50 \%)$ could be attributed to the creation of indirect fracture paths that reduced the stress propagation in the NFRPCs composite making it more impact resistant. In a related study Feng et al., [26] reported that kenaf -fibre/ maleated-polypropylene composite showed tremendous improvement in their impact strength. In the study of Wambua et al, [27] he showed that the impact strength of coir jute and kenaf composite showed higher impact strength. In their study Jawaid et al. [38] reported that the impact strength of jute/OPEFBs hybrid epoxy composite was greatly influenced by the glass fibres incorporated in the hybrid composite [35]. The slightly lower impact resistance recorded at $A$ compared to that at $B(C F: 10 \%)$ could be attributed to more void contents and poor interfacial bonding between $\mathrm{CF}$ and polymer matrix, agglomeration and fibre pullout, resulting in crack propagation as stress was applied to the NFRPCs reducing its impact strength [39].

\subsection{Biodegradation of NFRPCs}

Figure 3 showed the biodegradation of wPP and the NFRPCs. The biodegradation rates at 6 mths were $0.65 \%, 2.50 \%, 2.60 \%, 2.63 \%$ and $2.95 \%$ for CT, A, B, C, D and E respectively. CT showed near negligible biodegradation for all the months, this was because of the highly crystalline nature of polypropylene which resists the ingress of water, high molecular mass, and the presence of carbon -carbon and carbon-hydrogen non-polar bonds. The chains of polypropylene are densely packed forming highly crystalline regions which make it difficult for water and oxygen to diffuse into the region making the polymer highly resistant to attack of microorganisms. However with the addition of $\mathrm{CF}$ in the matrix of the polymer there was increased diffusion of water and oxygen into the matrix of the composites increasing the rate of microbial attack and degradation which was clearly reflected in the increased rate of biodegradation as the quantity of CF in the composite increased [28].

The higher rate of biodegradation in the NFRPCs was as a result of the suitable environment created by the $\mathrm{CF}$ for microorganisms to thrive. Higher amount of $\mathrm{CF}$ created larger surface areas and more water was available due to increased absorption making hydrolysis, photothermal and biodegradation degradation to readily take place in the NFRPCs. In a related research Ojeda et al., [29] showed that samples treated with cobalt showed higher level of degradation than films that were treated with cobalt.

It was shown in a study that the starch removal was higher for blends containing higher amount of starch (52\% and 67\%) and reached biodegradable completion in 40 days than samples containing lower amount of starch (29\%) showing that the higher amount of organic materials in 
the polymer matrix increased biodegradation significantly [41]. In another study, Orhan et al., [40] there was detection of significant evolution of carbon dioxide for the polyethylene-starch blend treated with $P$. chrysosporium even in the absence of an initial oxidative attack.

In another research [42], it was shown that the polyethylene samples treated with cobalt produced biofilms in the form of darkened spots on their surface when subjected to weathering for 1 year compared to films that were not treated with cobalt.

From the results above it can be inferred that natural fibres alone cannot make the biodegradation rate rapid for commercial application, additive may still need to be incorporated into the polymer to bring about rapid degradation when they are disposed.

Generally, the degradation of polyethylene is usually initiated at the weak sites (Karlsson and Albertsson [28]) and move on to produce hydro peroxide intermediates which produces carbonyl compounds leading to chain breakage and reduction in mechanical properties (Albertsson [43]; Albertsson et al. [44]) as indicated in Figure 4.

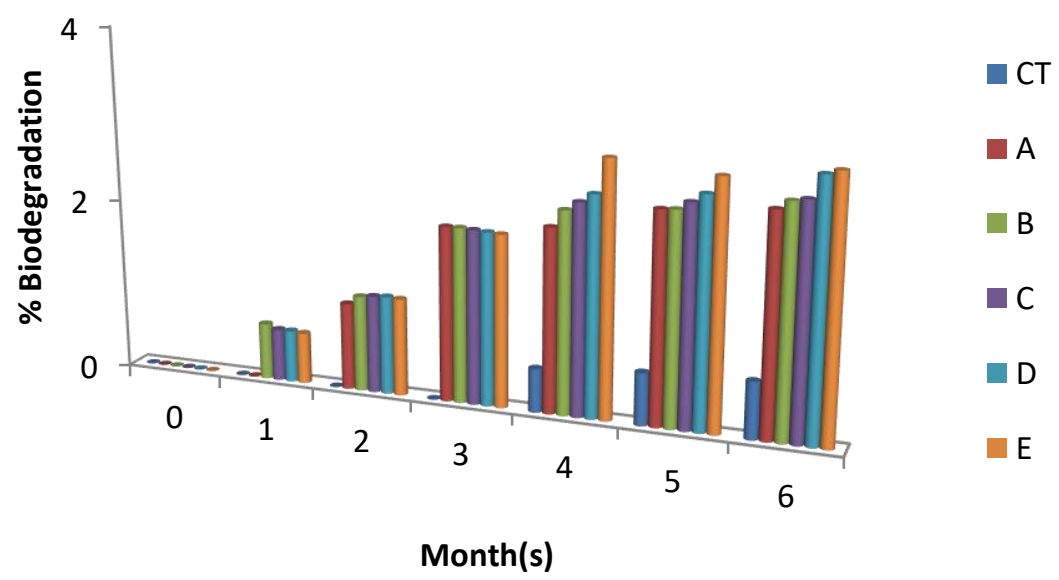

Figure 3: \% Biodegradation of composites

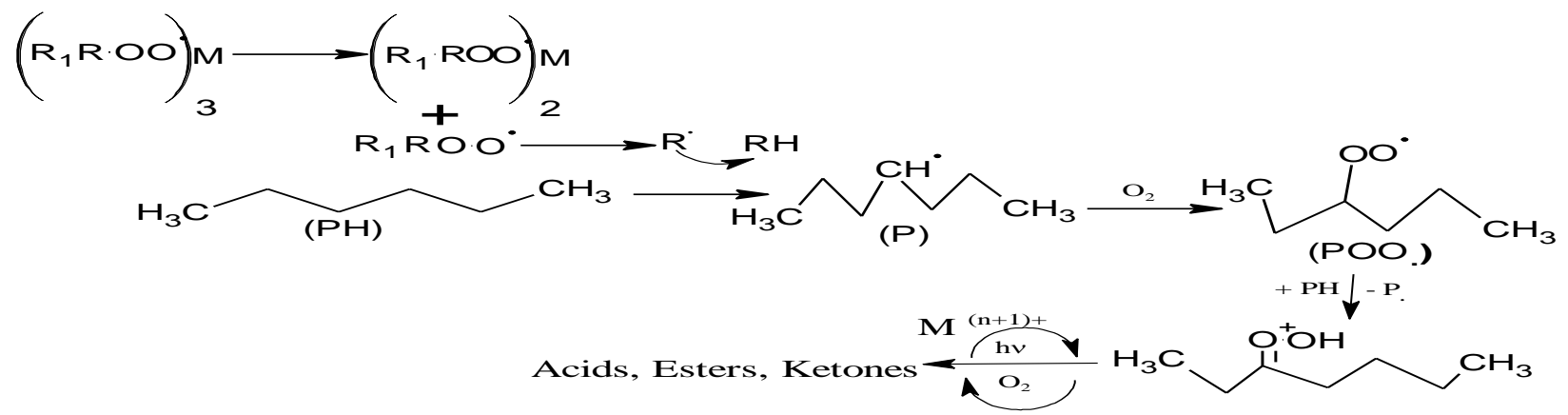

Figure 4: Transition metal induced biodegradation of a polymer [30] 


\subsection{SEM Analysis of Tensile Fractured Surface}

Debonding and fibre pull out were experienced in Plates (a), (b) and (c) which was as a result of poor adhesion between matrix and fibre. However debonding and fibre pull out were more pronounced in Plates (a) and (b) compared to Plate (c). This result was reflected in the mechanical properties test showing sample E with better mechanical properties compared to other NFRPCs. The surface of the pulled out fibres in plate (a) were neat without any matrix attached to the surface, while plate (b) showed a mixture of neat and rough surface, where some particles of the matrix adhered to the surface of pulled out fibre. Plate (c) on the other hand showed mostly rough surface indicating a better adhesion between matrix and fibre. The introduction of more $\mathrm{CF}$ as indicated in plate (c) created a more densified structure where the $\mathrm{CF}$ created some cross link within the chains of the polymer making them stiffer and at the same time improving the mechanical properties. This cross linked effect increased as the CF in the composite increased as indicated in the mechanical tests. The plates also showed void spaces in the morphology of the composite, these void spaces are responsible for the lower densities experienced in the NFRPCs compared to wPP. In a related study Mohanty et al., [31] the SEM analysis carried out on sisial-polypropylene composite showed that fibre matrix adhesion increased the mechanical properties of the composite.

CT showed that there was no prominent gaps in the structure which showed a good mixture during processing (Tong et al. [44]), CT also showed ductile tearing mode (Atiqah et al. 2014). The crystalline nature of the polymer which consists little branching restricts the movement of side groups and this helps to resist deformation Atiqah et al. [45]. Generally Fibre pullouts and debonding was experienced in the NFRPCs as a result of poor adhesion between fibre and matrix. Fibre pullouts were more pronounced in Sample C and Sample E as a result of higher quantities of $\mathrm{CF}$ in the composite, this lead to a more densified structure which reflected in the increase in mechanical properties of these NFRPCs. A few of the fibres surfaces that pulled out as shown in Samples A, B and C were as a result of poor adhesion between matrix and fibre [35].

\section{Conclusion}

Present study focused on the production of NFRPCs with wPP and CF. The effects of CF on the physico- mechanical properties of the NFRPCs were evaluated. The properties evaluated were tensile strength and modulus, flexural strength and modulus, densities, impact strength and \% water absorption of the NFRPCs. The following conclusions were made on the basis of the present study: 

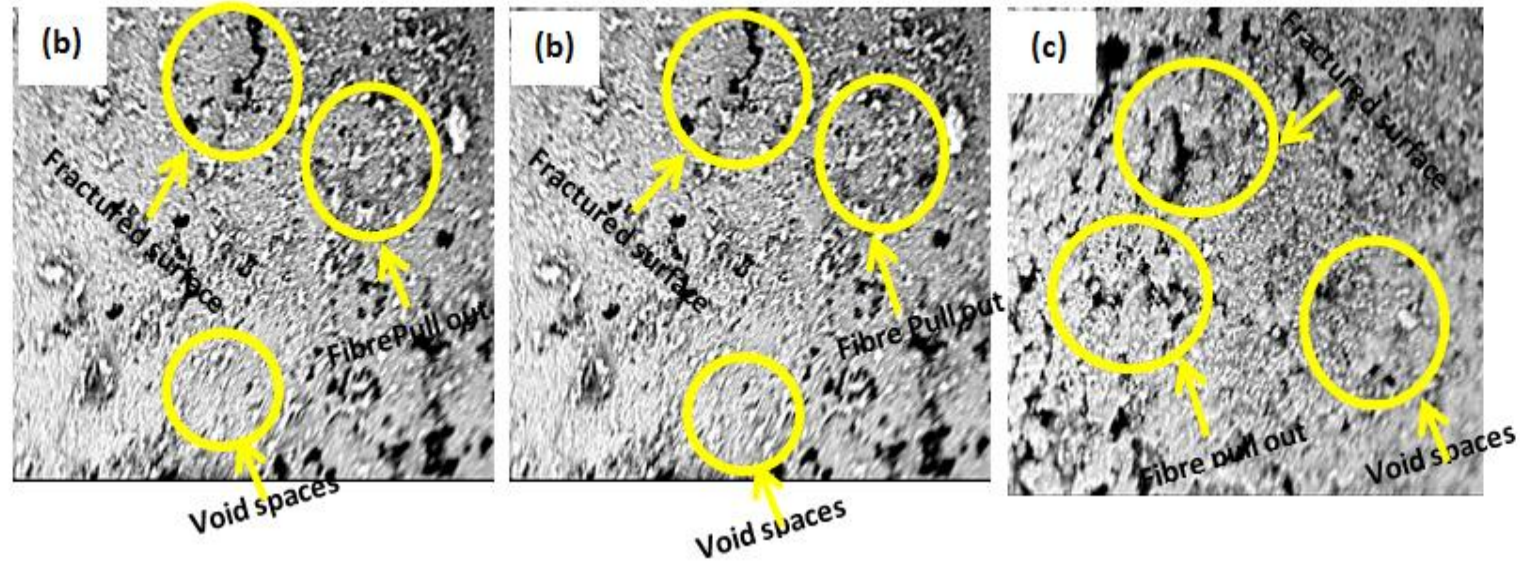

Plate (a): Sample A at 1000× magnification; Plate (b): Sample C at 1000× magnification; Plate

(c): Sample E at $1000 \times$ magnification

1. The NFRPCs showed increase in tensile and flexural strength with increase in CF due to good interfacial adhesion, relatively good dispersion of fibre and good stress transfer between the polymer matrix and the and $\mathrm{CF}$.

2. The NFRPCs showed increase in tensile modulus and flexural modulus with increase in $\mathrm{CF}$ due to good interfacial bonding between the matrix and the $\mathrm{CF}$ which introduced some level of cross link in the matrix of the NFRPCs making them more resistant to bending force.

3. The NFRPCs showed increase in impacts strength with increase in CF due to good packing density of the CF within the matrix of the composite giving it a higher capacity to absorb more energy.

4. The NFRPCs showed increase in \% water absorption with increase in in CF due to the hydrophilic polar nature of the $\mathrm{CF}$ which has hydroxyl groups that could easily bound to water.

5. The NFRPCs showed reduction in density with increase in CF due to dispersion problems which resulted in void spaces within the matrix of the NFRPCs.

6. The rate of biodegradation in the NFRPCs was higher than CT due to the increased diffusion of water and oxygen into the matrix of the NFRPCs making them more prone to microbial attack and degradation.

7. SEM results revealed void spaces in the NFRPCs which contributed to the lower densities experienced in the NFRPCs.

\section{REFERENCES}

[1] Moriana, R., Vilaplana, F., Karlsson, S., and Ribes, A. (2014). Correlation of chemical, structural and thermal properties of natural fibres for their sustainable exploitation. Carbohydrate Polymers, 112, 422-431. https://doi.org/10.1016/j.carbpol.2014.06.009

[2] Frackowiak, S., Ludwiczak, J., and Leluk, K. (2018). Man- made and natural fibres as a reinforcement in fully biodegradable polymer composites: A concise study. Journal of Polymers and the Environment, 26(12), 4360-4368. https://doi.org/10.1007/s10924-018- 


\section{1-9}

[3] Habibi, Y., El-Zawawy, W.K., Ibrahim, M.M., and Dufresne, A. (2008). Processing and characterization of reinforced polyethylene composites made with lignocellulosic fibers from Egyptian agro-industrial residues. Compos. Sci. Technol. 68 (7), 1877-1885.

[4] May-Pat, A., Valadez-Gonz'alez, A., and Herrera-Franco, P. J. (2013). Effect of fiber surface treatments on the essential work of fracture of HDPE-continuous henequen fiberreinforced composites. Polymer Testing, 32(6), 1114-1122.

[5] Ticoalu, A., Aravinthan, T., and Cardona, F. (2010, November). "A review of current development in natural fiber composites for structural and infrastructure applications,". In Proceedings of the Southern Region Engineering Conference (SREC '10), pp. 113117, Toowoomba, Australia.

[6] Nourbakhsh, A., Ashori, A., Ziaei, T. H., and Rezaei, F. (2010). Mechanical and thermo-chemical properties of wood-flour/polypropylene blends. Polymer Bulletin, 65(7), 691-700. https://doi.org/10.1007/s00289-010-0288-8

[7] Xie, Y., Hill, C.A.S., Xiao, Z., Militz, H., and Mai, C. (, 2010). "Silane coupling agents used for natural fiber/polymer composites: a review," Composites Part A: Applied Science and Manufacturing, vol. 41, no. 7, pp. 806-819

[8] Väisänen, T., Haapala, A., Lappalainen, R., and Tomppo, L. (2016). Utilization of agricultural and forest industry waste and residues in natural fiber-polymer composites: A review. Waste Management, 54, 62-73. https://doi.org/10.1016/j.wasman.2016.04.037

[9] Višnjić, D., Lalić, H., Dembitz, V., and Banfić, H. (2014). Metabolism and differentiation. Periodicum Biologorum, 116(1), 37-43. https://doi.org/10.1002/pc

[10] Thakur, V. K., Thakur, M. K., and Pappu, A. (2017). Hybrid Polymer Composite Materials (1st Edition). Cambridge MA, United States. https://doi.org/10.1016/B978-008-100791-4.00013-6

[11] Ray, S. S., and Bousmina, M. (2005). Biodegradable polymers and their layered silicate nano composites: in greening the 21st century materials world," Progress in Materials Science, vol. 50(8) 962-1079.

[12] Faruk, O., Bledzki, K., Fink, H.P., and Sain, M. (2012). "Biocomposites reinforced with natural fibers: 2000-2010," Progress in Polymer Science, 37(11), 1552-1596.

[13] Shinoj, S., Visvanathan, R., Panigrahi, S., and Kochubabu, M. (2011). "Oil palm fiber (OPF) and its composites: a review," Industrial Crops and Products, 33, (1) 7-22.

[14] Ashori. A., and Nourbakhsh, A. (2008). A comparative study on mechanical properties and water absorption behavior of fiber-reinforced polypropylene composites prepared by OCC fiber and aspen fiber. Polymer Composites, (29), 574-578. https://doi.org/DOI $10.1002 /$ pc. 20582

[15] Koshti, R., Mehta, L., and Samarth, N. (2018). Biological recycling of polyethylene terephthalate: A mini-review. Journal of Pol ymers and the Environment, 26(8), 35203529. https://doi.org/10.1007/s10924-018-1214-7

[16] Cacciari, I., Quatrini, P., Zirletta, G., Mincione, E., Vinciguerra, V., Lupatelli, P., and Sermanni, G. G. (1993). Isotactic polypropylene biodegradation by a microbial community: Physicochemical charac- terization of metabolites produced. Applied and Environmental Microbiology, 59(11): 3695-3700.

[17] Witt, U., Muller, R. J., and Deckwer, W. D. (1997). Biodegradation behavior and material properties of aliphatic/aromatic polyesters of commercial importance. Journal of Environmental Polymer Degradation 15: 81-89. 
[18] Yayasekara, R., Harding, I., Bowater, I., and Lonergan, G. (2005). Biodegradability of selected range of polymers and polymer blends and standard methods for assessment of biodegradation. Journal of Polymer Environment, 13: 231.

[19] Devi, R., Kannan, V., Natarajan, K., Nivas, D., Kannan, K., Chandru, S., and Antony, A. (2015). The Role of Microbes in Plastic Degradation. Environmental Waste Management. https://doi.org/10.1201/b19243-13

[20] Katchy, E. M. (2000). Principles of Polymer Science (1st edition). Enugu, Nigeria. El' Demak. Chap 11, 261-302.

[21] Dan-asabe, B. (2016). Thermo-mechanical characterization of banana particulate reinforced PVC composite as piping material. Journal of King Saud University Engineering Sciences, 30(4), 296-304. https://doi.org/10.1016/j.jksues.2016.11.001P

[22] Sreekala, S.M., and Thomas, S. (2003). "Effect of fibre surface modification on watersorption characteristics of oil palm fibres," Composites Science and Technology, 63(6), 861-869.

[23] Xu, K., Tu, D., Chen, T., Zhong, T., and Lu, J. (2016). Effects of environmental- friendly modified rubber seed shell on the comprehensive properties of high density polyethylene/rubber seed shell composites. Ind Crops Prod 91, 132-141

[24] Shalwan, A., and Yousif, B. F. (2013). "In state of art: mechanical and tribological behaviour of polymeric composites based on natural fibres," Materials \& Design, 48, 14-24.

[25] Mohanty, A. K., Khan, M. A., and Hinrichsen, G. (2000). "Surface modification of jute and its influence on performance of biodegradable jute-fabric/Biopol composites," Composites Science and Technology, 60( 7) 1115-1124.VIS*

[26] Feng, Daan, Caulfield, D.F., and Sanadi, A.R. (2001). Effect of compatibilizer on the structure-property relationships of kenaf fiber/polypropylene composites. J. Polym. Compos. 22 (4), 506-517.

[27] Wambua, Paul, Ivens, Jan, Verpoest, Ignaas. (2003). Natural fibers: can they replace glass in fiber reinforced plastics. Compos. Sci. Technol. 63, 1259-1264.

[28] Karlsson, S., and Albertsson, A. (1998). Biodegradable polymers and environmental interaction. Polymer Engineering and Science, 38(8), 1251-1253. Doi:10.1002/pen.10294

[29] Ojeda, T. F. M., Dalmolin, E., Forte, M. M. C., Jacques, R. J. S., Bento, F. M., and Camargo, F. A. O. (2009). Abiotic and biotic degradation of oxobiodegradable polyethylenes. Polym. Degrad. Stab, 94 (6), 965-970.

[30] Roy, P. K., Hakkarainen, M., Varma, I. K., and Albertsson, A. (2011). Degradable polymers:

Fantacy or reality. Environmental Science and Technology, 45, 4217-4227. Doi: 10.1021/es104042f

[31] Mohanty, S., Nayak, S.K., Verma, S.K., and Tripathy, S.S. (2004). Influence of fiber treatment on the performance of sisal-polypropylene composites. J. Appl. Polym. Sci.94 (3), 1336-1345

[32] Ou R, Zhao H, Sui S, Song Y, Wang Q (2010) Reinforcing effects of Kevlar fibre on the mechanical properties ofcomposite using rice husk filler. Adv Mater Sci Eng 2014:1-6. https ://doi.org/10.1155/2014/93896 1

[33] Prasanth I. S. N. V. R., Ravishankar D. V., Hussain, M. M., Badiganti, C, M., Sharma V. K., and Pathak, S. (2018). Investigations on performance characteristics of GFRP composites in milling. The International Journal of Advanced Manufacturing Technology .99, 1351-1360 https://doi.org/10.1007/s00170-018-2544-2 
[34] Naresh N, Jenarthanan MP, and Prakash RH (2014) Multi-objective optimization of CNC milling process using Grey-Taguchi method in machining of GFRP. composites.MultidiscipModelMater Struct 10(2):265-275

[35] Ejiogu, I. K., Ibeneme, U., Ishidi, E. Y., Osi Gabriel Tenebe, O. G., and Ayo, M.D (2019). Biodegradable hybrid polymer composite reinforced with coconut shell and sweet date seed (Phoenix dactylifera) powder: a physico-mechanical study; part A. Multiscale and Multidisciplinary Modeling, Experiments and Design, https://doi.org/10.1007/s41939-019-00060-3

[36] Agarwal BD, Broutman LJ, Chandrashekhara K (2017) Analysis and performance of fiber composites, 3rd edn. Wiley, New York

[37] Abdul KHPS, Fizree HM, Jawaid M, Omar SA (2011) Preparation and characterization of nano-structured materials from oil palm ash: a bio-agricultural waste from oil palm mill. Bio-Resour. 6(4):4537-4546

[38] Jawaid M, Abdul-Khalil HA, Bakar AA (2010) Mechanical performance of oil palm empty fruit bunches/jute fibres reinforced epoxyhybrid composites. Mater Sci Eng A 527(29-30):7944-7949

[39] Saba N, Tahir PM, Jawaid M (2014) A review on potentiality of nano filler/natural fiber filled polymer hybrid composites. Polymers 6(8):2247-2273

[40] Orhan Y, Buyukgungor H (2000) Enhancement of biodegradability of disposable polyethylene in controlled biological soil. Int Biodeterior Biodegrad 45(12):49-55

[41] Karlsson S, Albertsson A (1998) Biodegradable polymers and environmental interaction. Polym Eng Sci 38(8):1251-1253. https ://doi.org/10.1002/pen.10294

[42] Ojeda TFM, Dalmolin E, Forte MMC, Jacques RJS, Bento FM, Camargo FAO (2009) Abiotic and biotic degradation of oxobiodegradable polyethylenes. Polym Degrad Stab 94(6):965-970

[43] Albertsson AC (1980) The shape of the biodegradation curve for low and high-density polyethenes in prolonged series of experiments. Eur Polym J 16(7):623-630.

[44] Tong JY, Royan RRN, Ng YC, Ab Ghani MH, Ahmad S (2014) Study of the mechanical and morphology properties of recycled HDPE

[45] Atiqah AASM, Salmah H, Firuz Z, Lan DNU (2014) The effect of blend ratio on properties of recycled polypropylene/recycled high density polyethylene Geocomposites. Malays J Anal Sci 18(2):344-350 composite using rice husk filler. Adv Mater Sci Eng 2014:1-6.https ://doi.org/10.1155/2014/93896 1 